\title{
Epidemiology, classification, treatment, and mortality of adult femoral neck and basicervical fractures: an observational study of 40,049 fractures from the Swedish Fracture Register
}

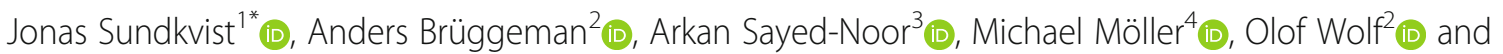
Sebastian Mukka' (1)

\begin{abstract}
Background: Although femoral neck fractures (FNFs) are common in orthopedic departments, optimal treatment methods remain in dispute. There are few large nationwide studies, including basicervical FNFs (bFNFs), on epidemiology, treatment, and mortality. This nationwide study aims to describe the epidemiology, fracture classification, current treatment regimens, and mortality of undisplaced and minimally displaced (Garden I-II, uFNF), displaced (Garden III-IV, dFNF) and bFNFs in adults.

Methods: All FNFs, including bFNFs with a registered injury date between 1 April 2012 and 31 December 2020, were included in this observational study from the Swedish Fracture Register (SFR). Data on age, sex, injury mechanism, fracture classification, primary treatment, and seasonal variation were analyzed.
\end{abstract}

Results: Some 40,049 FNFs were registered in the SFR. The mean age of the patients in the register was 80.3 (SD $11)$ years and $63.8 \%(25,567)$ were female. Of all FNFs, $25.0 \%(10,033)$ were UFNFs, $63.4 \%(25,383)$ dFNFs, and $11.6 \%$ $(4,633)$ bFNFs. Non-surgical treatment was performed in $0.6 \%$ (261) of the patients. Internal fixation (IF) (84.7\%) was the main treatment for UFNFs and arthroplasty (87.3\%) for dFNFs. For bFNFs, IF (43.8\%) and hip arthroplasty (45.9\%) were performed equally often. Of the 33,105 patients with a 1-year follow-up mortality at 1-year was $20.6 \%$ for UFNF, 24.3\% for dFNF, and 25.4\% for bFNF.

Conclusion: The main treatment of UFNFs is IF with screws or pins. Hip arthroplasty is the predominant treatment for dFNF. bFNF are more common than previously reported and treated with IF or arthroplasty, depending on patient age. These results may help health care providers, researchers and clinicians better understand the panorama of FNFs in Sweden.

Level of Evidence: IV, retrospective cohort study.

\footnotetext{
* Correspondence: jonas.sundkvist@umu.se

'Department of Surgical and Perioperative Sciences, Orthopaedics, Umeå University, Umeå, Sweden

Full list of author information is available at the end of the article
}

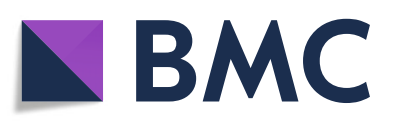

(- The Author(s). 2021 Open Access This article is licensed under a Creative Commons Attribution 4.0 International License, which permits use, sharing, adaptation, distribution and reproduction in any medium or format, as long as you give appropriate credit to the original author(s) and the source, provide a link to the Creative Commons licence, and indicate if changes were made. The images or other third party material in this article are included in the article's Creative Commons licence, unless indicated otherwise in a credit line to the material. If material is not included in the article's Creative Commons licence and your intended use is not permitted by statutory regulation or exceeds the permitted use, you will need to obtain permission directly from the copyright holder. To view a copy of this licence, visit http://creativecommons.org/licenses/by/4.0/ The Creative Commons Public Domain Dedication waiver (http://creativecommons.org/publicdomain/zero/1.0/) applies to the data made available in this article, unless otherwise stated in a credit line to the data. 


\section{Introduction}

Femoral neck fractures (FNFs) are a subset of proximal femoral fractures commonly encountered in orthopedic practice with significant morbidity and mortality [1]. FNFs are mainly classified into undisplaced or minimally displaced (Garden 1-2, uFNF) and displaced fractures (Garden 3-4, dFNF). A third, less studied category of fractures is the basicervical FNFs (bFNFs), defined as fractures through the base of the femoral neck at their junction with the intertrochanteric region [2].

The treatment of FNFs in patients $>60$ years is still under debate [3-5]. The treatment of uFNFs has primarily consisted of internal fixation (IF). However, recently, hip arthroplasty has been proposed as a viable option to reduce reoperation rates and possibly improve functional outcome $[3,6]$. The type of arthroplasty to be usedhemi- or total hip arthroplasty in the treatment of dFNF in elderly patients remains controversial [7]. The incidence and treatment of bFNFs has been found to vary notably $[8-10]$.

This study describes the injury mechanism, fracture classification, sex and age distribution, seasonal variation, and primary treatment in patients with fracture along the anatomical femoral neck using the Swedish Fracture Register (SFR).

\section{Materials and methods}

\section{Study design and setting}

This observational register study was designed based on data derived from the SFR.

The SFR, established in 2011, is a national quality register for the management of fractures and treatment. Detailed data on patient and fracture characteristics, injury mechanism, and fracture treatment are recorded in each affiliated department via a pre-specified digital form by the treating physician. Only patients with a permanent Swedish personal identification number and fractures that have occurred in Sweden are registered. In the SFR, fractures are mainly classified according to the AO/OTA classification system. Several studies have found the registration in the SFR to have high accuracy and validity [11]. The proportion of departments affiliated with the SFR has increased gradually; in January 2014, 40\% of affiliated departments were active. As of 1 January 2021, all orthopedic departments $(n=54)$ in Sweden are engaged in the SFR, i.e., $100 \%$ coverage. More than 500,000 fractures had been registered by the end of 2020 .

The registration of FNFs in the SFR includes uFNFs (Garden 1-2, AO/OTA 31-B1), dFNFs (Garden 3-4, AO/OTA 31-B3) and bFNFs (AO/OTA 31-B2). Information is available on peri-implant and periprosthetic fractures (UCS classification) and open fractures based on the Gustilo-Anderson classification. The injury mechanism includes information on stress, spontaneous and pathological fractures. Treatment is registered with the chosen type of therapy (non-operative or operative). Operative treatments consist of fracture fixation, including types of osteosynthesis (screws or pins, sliding hip device (SHD), long and short intramedullary nails (IMNs), anatomic plates), arthroplasty (hemi- or total, cemented or cementless fixation), or other (i.e., excision arthroplasty).

\section{Patient selection}

All non-pathological FNFs (ICD code S72.00/S72.01) in adults registered in the SFR between 1 April 2012 and 31 December 2020 were included. We included bilateral FNFs and excluded peri-implant, periprosthetic, and pathological fractures.

\section{Study variables}

Epidemiological data on age, sex, injury date, injury mechanism and type (high or low energy) trauma, fracture classification (type, side, open/closed fracture), treatment, and mortality were analyzed. The injury mechanism was categorized as a simple fall, an unspecified fall, a transportation accident or any other cause. Primary treatment was studied in the following groups: IF with screws or pins, IMNs, SHD or hip arthroplasty (hemi- or total), or other (i.e., excision arthroplasty).

\section{Statistics}

Variables are presented as the proportion of all fractures (\%), i.e., the available number of inputs in the register excluding any missing values.

Nominal variables are presented as proportions of all fractures and scale variables as means \pm standard deviation $( \pm \mathrm{SD})$. An independent sample $t$ test was used to compare scale variables. For the log-rank test $p<0.05$ was considered significant.

Data analysis was performed with $\mathrm{R}$ statistical software, version 4.0.4.

\section{Ethics}

The study was approved by the Swedish Ethical Review Authority (dnr: 2020-05439) and carried out according to the Helsinki Declaration.

\section{Results}

\section{Study patients and descriptive data}

In total, 86,083 proximal femoral fractures were extracted from the SFR (ICD-10 S72.0-4). After exclusion, 40,049 FNFs were included for further analysis (Fig. 1). Some $3.7 \%(n=1474)$ of the patients sustained bilateral FNFs during the study period. Of all fractures, $63.8 \%$ occurred in females (Table 1, Fig. 2). Females (mean age 81.3 years, $\mathrm{SD} \pm 10$ ) were older than men (78.7 years, $\mathrm{SD} \pm 12, p<0.001)$. Simple falls were the most common injury mechanism (79.9\%). A minority of fractures were 


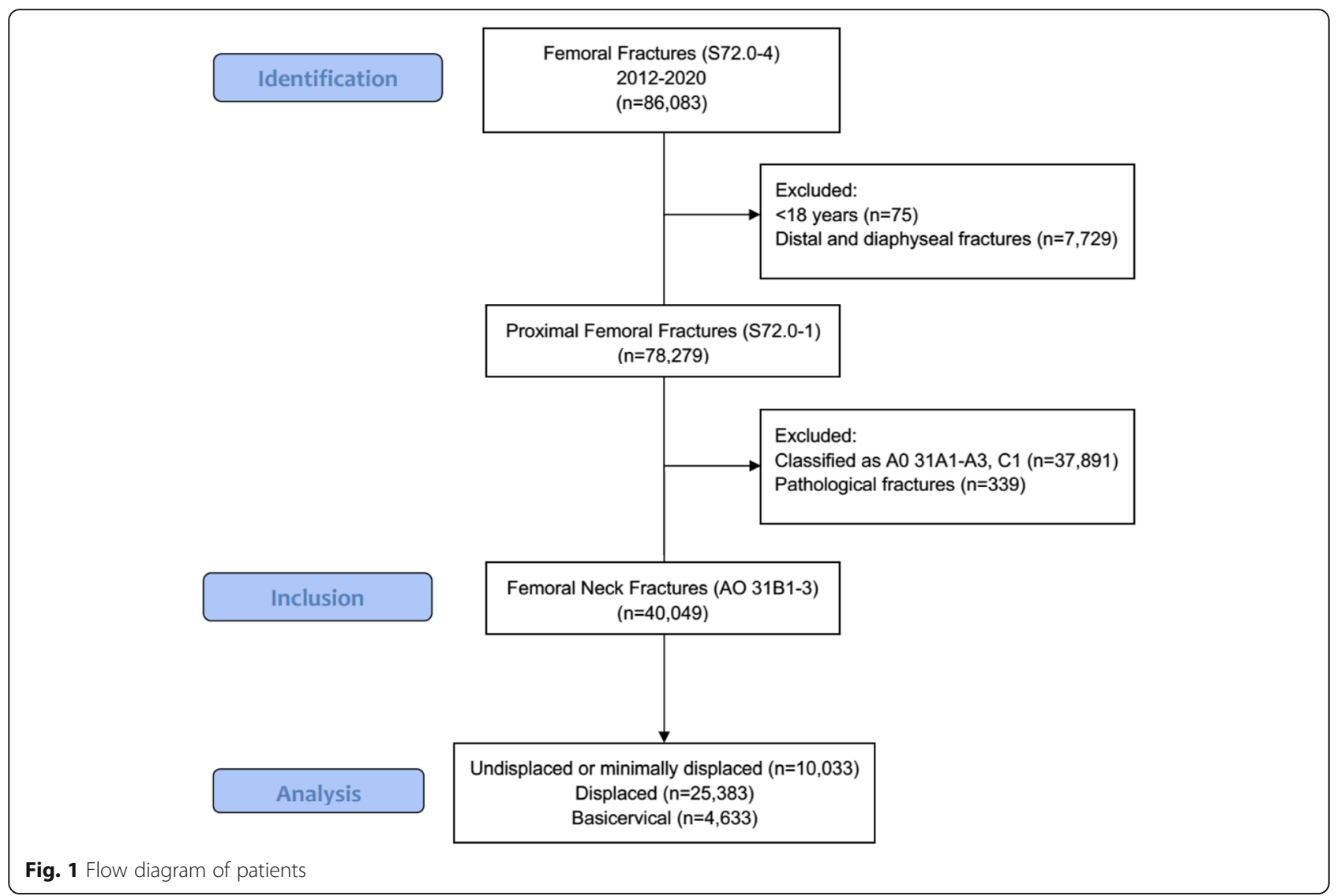

caused by high-energy trauma: $11.0 \%$ of the patients < 60 years of age and $0.6 \%>60$ years (Table 2). Some $5.8 \%$ were stress fractures in patients $<60$ years and $1.1 \%$ in patients $>60$ years. Most fractures occurred in the patients' immediate environment (own home 50.1\% or institution $14.4 \%$ ).

\section{Seasonal variation}

Both women and men appeared to sustain fewer fractures in temperate months (47.9\%, April to September), and there was an observed slight increase in the colder months (52.1\%, October to March).

\section{Fracture classification}

Of all FNFs, $25.0 \%(10,033)$ were uFNFs, $63.4 \%(25,383)$ dFNFs, and $11.6 \%$ (4633) bFNFs.

In all three fracture types, men represented a majority in the age group $<60$ years, whereas women represented the majority in the age group $>60$ years (Table 2).

\section{Treatment}

The method of surgical treatment differed between age groups and type of FNF (Table 3): patients $<60$ years were mostly treated with IF for all types of FNF (74.3\%).
Patients $>60$ years with uFNFs were largely treated with IF (84.2\%), and to a much lesser extent, with hip arthroplasty (9.6\%). Most patients $>60$ years with a dFNF were treated with hip arthroplasty (89.4\%), whereas IF was uncommon (6.8\%).

Some $74.9 \%$ of the patients with bFNFs who were $<60$ years of age were treated with IF (45.0\% SHD) and 13\% in this age group were treated with hip arthroplasty. Some $48.2 \%$ of the patients $>60$ years with a bFNFs received a hip arthroplasty and $41.6 \%$ were treated with IF (7.0\% screws or pins, $28.6 \%$ SHD).

\section{Mortality}

Of the 33,105 patients with a 1-year follow-up mortality for uFNF at 7-, 30-day, and 1-year mortality was $5.3 \%$, $10.5 \%$, and $20.6 \%$. For dFNF 7-, 30-day, and 1-year mortality was $7.7 \%, 13.6 \%$, and $24.3 \%$. For bFNF 7-, 30-day, and 1-year mortality was $7.9 \%, 15.7 \%$, and $25.4 \%$. Kaplan-Meier curves are presented in Fig. 3.

\section{Discussion}

The main findings of this study on data from the SFR are that the proportion of bFNFs is larger than previously described. The treatment varies between fracture groups but also depends on age. More men than women 
Table 1 Patient characteristics. Distribution of sex, age, injury mechanism, type of trauma, and location

\begin{tabular}{|c|c|c|c|c|}
\hline & $\begin{array}{l}\text { Undisplaced or minimally displaced FNF } \\
(n=10,033)\end{array}$ & $\begin{array}{l}\text { Displaced FNF } \\
(n=25,383)\end{array}$ & $\begin{array}{l}\text { Basicervical FNF } \\
(n=4633)\end{array}$ & $\begin{array}{l}\text { All patients } \\
(n=40,049)\end{array}$ \\
\hline Age $^{*}$ & $78.5( \pm 12.0)$ & $81.1( \pm 10.4)$ & $80.2( \pm 12.0)$ & $80.3( \pm 11.0)$ \\
\hline Female $^{\dagger}$ & 6,614 (65.9\%) & 16,290 (64.2\%) & 2663 (57.5\%) & 25,567 (63.8\%) \\
\hline \multicolumn{5}{|l|}{ Mechanism ${ }^{\dagger}$} \\
\hline Bicycle $^{\dagger}$ & 92 (2.0\%) & 481 (1.9\%) & $92(2.0 \%)$ & 872 (2.2\%) \\
\hline Fall from height & $288(2.9 \%)$ & 687 (2.7\%) & $128(2.8 \%)$ & $1103(2.8 \%)$ \\
\hline Fall same level & 7857 (78.3\%) & $20,521(80.8 \%)$ & 3639 (78.5\%) & 32,017 (79.9\%) \\
\hline Stress fracture ${ }^{\dagger}$ & 190 (1.9\%) & 277 (1.1\%) & 74 (1.6\%) & 541 (1.4\%) \\
\hline Other cause ${ }^{\ddagger}$ & $474(4.7 \%)$ & $1003(4.0 \%)$ & 247 (5.3\%) & $1724(4.3 \%)$ \\
\hline Unspecified fall $^{\dagger}$ & 925 (9.2\%) & 2414 (9.5\%) & 453 (9.8\%) & 3792 (9.5\%) \\
\hline \multicolumn{5}{|l|}{ Type of trauma } \\
\hline High energy & $117(1.2 \%)$ & $252(1.0 \%)$ & $75(1.6 \%)$ & 444 (1.1\%) \\
\hline Low energy & 8827 (88.0\%) & 22,569(88.9\%) & 3,963(85.5\%) & $35,359(88.3 \%)$ \\
\hline Not applicable ${ }^{\ddagger}$ & 190 (1.9\%) & $275(1.1 \%)$ & $74(1.6 \%)$ & 539 (1.3\%) \\
\hline Unknown & $183(1.8 \%)$ & $626(2.5 \%)$ & 143(3.1\%) & 952 (2.4\%) \\
\hline Missing & 716 (7.1\%) & $1,661(6.5 \%)$ & $378(8.2 \%)$ & 2755 (6.9\%) \\
\hline \multicolumn{5}{|l|}{ Location } \\
\hline Home & 4679 (46.6\%) & 13,000 (51.2\%) & 2389 (51.6\%) & $20,068(50.1 \%)$ \\
\hline Institution & 1334 (13.3\%) & 33,794 (14.9\%) & 644 (13.9\%) & $5772(14.4 \%)$ \\
\hline Public place & 409 (4.1\%) & 939 (3.7\%) & 167 (3.6\%) & 1515 (3.8\%) \\
\hline Street & $538(5.4 \%)$ & $1218(4.8 \%)$ & $188(4.1 \%)$ & 1944 (4.9\%) \\
\hline Other & 1137 (11.3\%) & 2006 (7.9\%) & 455 (9.8\%) & 3598 (9.0\%) \\
\hline Unspecified $^{\dagger}$ & 1936 (19.3\%) & 4426 (17.4\%) & 790 (17.1\%) & 7152 (17.9\%) \\
\hline
\end{tabular}

"The values are given as the mean and standard deviation

${ }^{+}$Values are given as the number of patients, with the percent in parentheses

${ }^{{ }^{*} \text { i.e., }}$ stress fracture

patients $<60$ years old sustained a fracture caused by high-energy trauma or stress fractures.

\section{Demographics}

As previously reported, more women than men sustain FNFs and females were older than men when the fracture occurs [1]. Most of the men were in the age group $\leq 60$ years, for which high-energy trauma is more common, representing $11 \%$ of all fractures. In line with a previous study, the incidence of FNFs increases gradually with age, with a marked increase after age 75 [12]. Stress fractures accounted for $5.8 \%$ in the younger age group and have previously been reported mainly among military personnel in similar numbers [13]. These fractures are of interest due to their different background and typically delayed diagnosis with continued activity and risk of further displacement and worse long-term outcome [14]. Early diagnosis of stress fractures is essential to avoid serious complications. Persistent groin pain following exercise is a symptom worthy of attention and warrants thorough radiographic examination [15].

\section{Seasonal variation}

The incidence of all fracture types varied over the calendar year. A slightly higher occurrence of FNFs was seen during the winter months (October-March) in both men and women. These results are supported by a report on seasonal variation of hip fractures [16]. Most hip fractures occur due to indoor falls and not slipping on icy roads or pavements, but the incidence has been proposed to increase with latitude and vary with season [17]. Vitamin D insufficiency has been suggested to influence fracture pathogenesis, particularly in northern climates [16]. The limited daylight in the northern latitudes during the winter months can potentially increase the risk of falls. There are contradictory reports of latitude on the risk of hip fracture incidence [18].

\section{Fracture classification}

The classification of femoral fractures in the SFR is substantial (AO/OTA group) to almost perfect (AO/OTA type) and as accurate as in previous studies [11]. The SFR and AO/OTA currently do not support further 


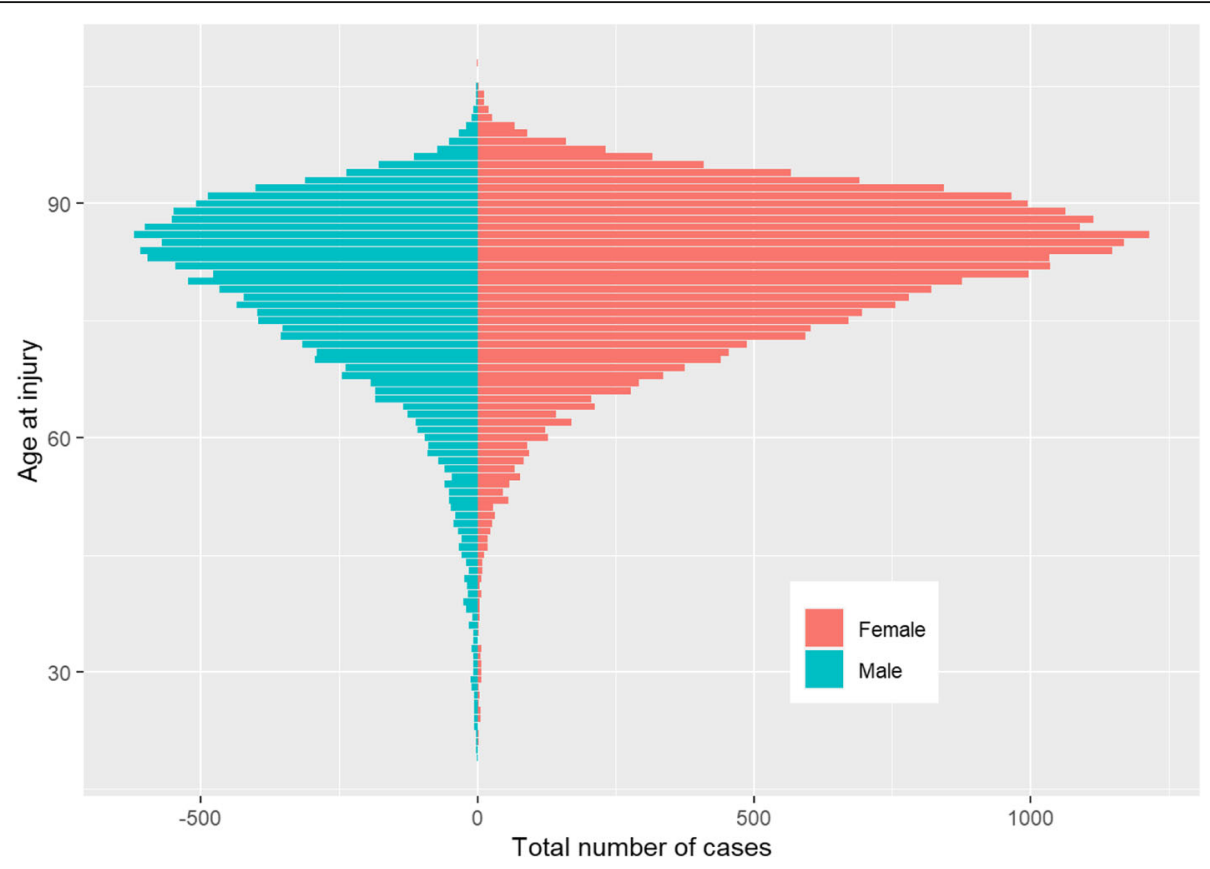

Fig. 2 Distribution of age at injury

Table 2 Patient characteristics: distribution of sex, age at injury, injury mechanism, type of trauma and location stratified for patients $\leq 60$ years of age at injury and those $>60$ years

\begin{tabular}{|c|c|c|c|c|c|c|c|c|}
\hline & \multicolumn{2}{|c|}{$\begin{array}{l}\text { Undisplaced or minimally } \\
\text { displaced FNF }\end{array}$} & \multicolumn{2}{|c|}{ Displaced FNF } & \multicolumn{2}{|c|}{ Basicervical FNF } & \multicolumn{2}{|l|}{ All fractures } \\
\hline & $\begin{array}{l}<=60 \\
(N=791)\end{array}$ & $\begin{array}{l}>60 \\
(N=9242)\end{array}$ & $\begin{array}{l}<=60 \\
(N=1028)\end{array}$ & $\begin{array}{l}>60 \\
(N=24,355)\end{array}$ & $\begin{array}{l}<=60 \\
(N=307)\end{array}$ & $\begin{array}{l}>60 \\
(N=4326)\end{array}$ & $\begin{array}{l}<=60 \\
(N=2126)\end{array}$ & $\begin{array}{l}>60 \\
(N=37,923)\end{array}$ \\
\hline Age (mean, SD) & $50.6(9.31)$ & 80.9 (8.73) & $51.8(8.44)$ & $82.4(8.42)$ & $49.8(9.69)$ & $82.3(8.72)$ & $51.1(8.99)$ & $82.0(8.56)$ \\
\hline \multicolumn{9}{|l|}{ Sex } \\
\hline Female & 388 (49.1\%) & 6226 (67.4\%) & 461 (44.8\%) & 15,829 (65.0\%) & 133 (43.3\%) & 2530 (58.5\%) & $982(46.2 \%)$ & $24,585(64.8 \%)$ \\
\hline \multicolumn{9}{|l|}{ Side } \\
\hline Left & 401 (50.7\%) & 4649 (50.3\%) & $553(53.8 \%)$ & 12,952 (53.2\%) & 152 (49.5\%) & 2184 (50.5\%) & 1106 (52.0\%) & 19,785 (52.2\%) \\
\hline \multicolumn{9}{|l|}{ Mechanism } \\
\hline Fall same level & 465 (58.8\%) & $7392(80.0 \%$ & $630(61.3 \%)$ & 19,891 (81.7\%) & 163 (53.1\%) & 3476 (80.4\%) & 1258 (59.2\%) & $30,759(81.1 \%)$ \\
\hline Fall from height & $46(5.8 \%)$ & $242(2.6 \%)$ & 61 (5.9\%) & $626(2.6 \%)$ & $20(6.5 \%)$ & 108 (2.5\%) & 127 (6.0\%) & 976 (2.6\%) \\
\hline Unspecified fall & $45(5.7 \%)$ & $880(9.5 \%)$ & $83(8.1 \%)$ & $2,331(9.6 \%)$ & $23(7.5 \%)$ & 430 (9.9\%) & $151(7.1 \%)$ & 3641 (9.6\%) \\
\hline Bicycle & 95 (12.0\%) & 204 (2.2\%) & 90 (8.8\%) & 391 (1.6\%) & 30 (9.8\%) & $62(1.4 \%)$ & $215(10.1 \%)$ & 657 (1.7\%) \\
\hline Stress fracture & $60(7.6 \%)$ & 130 (1.4\%) & 30 (2.9\%) & 247 (1.0\%) & 34 (11.1\%) & $40(0.9 \%)$ & $124(5.8 \%)$ & 417 (1.1\%) \\
\hline Other cause & 80 (10.1\%) & 394 (4.3\%) & 134 (13.0\%) & 869 (3.6\%) & 37 (12.1\%) & 210 (4.9\%) & $251(11.8 \%)$ & 1473 (3.9\%) \\
\hline \multicolumn{9}{|l|}{ Type of trauma } \\
\hline Low energy & $552(69.8 \%)$ & 8275 (89.5\%) & 759 (73.8\%) & $21,810(89.6 \%)$ & 191 (62.2\%) & 3772 (87.2\%) & 1502 (70.6\%) & 33,857 (89.3\%) \\
\hline High energy & 65 (8.2\%) & $52(0.6 \%)$ & $127(12.4 \%)$ & $125(0.5 \%)$ & 41 (13.4\%) & $34(0.8 \%)$ & $233(11.0 \%)$ & $211(0.6 \%)$ \\
\hline Not applicable & $60(7.6 \%)$ & 130 (1.4\%) & 30 (2.9\%) & 245 (1.0\%) & 34 (11.1\%) & $40(0.9 \%)$ & $124(5.8 \%)$ & 415 (1.1\%) \\
\hline Unknown & 42 (5.3\%) & 141 (1.5\%) & 46 (4.5\%) & $580(2.4 \%)$ & 18 (5.9\%) & 125 (2.9\%) & 106 (5.0\%) & 846 (2.2\%) \\
\hline Missing & 72 (9.1\%) & 644 (7.0\%) & 66 (6.4\%) & $1595(6.5 \%)$ & $23(7.5 \%)$ & 355 (8.2\%) & $161(7.6 \%)$ & 2594 (6.8\%) \\
\hline
\end{tabular}


Table 3 Treatment choice for the three fracture subgroups and overall fractures stratified by patients $\leq 60$ years of age at injury and those $>60$ years

\begin{tabular}{|c|c|c|c|c|c|c|c|c|}
\hline & \multicolumn{2}{|c|}{$\begin{array}{l}\text { Undisplaced or } \\
\text { minimally displaced } \\
\text { FNF }\end{array}$} & \multicolumn{2}{|c|}{ Displaced FNF } & \multicolumn{2}{|c|}{ Basicervical FNF } & \multicolumn{2}{|l|}{ All fractures } \\
\hline & $\begin{array}{l}<=60 \\
(N=791)\end{array}$ & $\begin{array}{l}>60 \\
(N=9242)\end{array}$ & $\begin{array}{l}<=60 \\
(N=1028)\end{array}$ & $\begin{array}{l}>60 \\
(N=24,355)\end{array}$ & $\begin{array}{l}<=60 \\
(N=307)\end{array}$ & $\begin{array}{l}>60 \\
(N=4326)\end{array}$ & $\begin{array}{l}<=60 \\
(N=2126)\end{array}$ & $\begin{array}{l}>60 \\
(N=37,923)\end{array}$ \\
\hline Hip Screws & $\begin{array}{l}671 \\
(84.8 \%)\end{array}$ & $\begin{array}{l}7,582 \\
(82.0 \%)\end{array}$ & $\begin{array}{l}599 \\
(58.3 \%)\end{array}$ & $1,554(6.4 \%)$ & $80(26.1 \%)$ & $302(7.0 \%)$ & $\begin{array}{l}1,350 \\
(63.5 \%)\end{array}$ & $9438(24.9 \%)$ \\
\hline Sliding hip device & $37(4.7 \%)$ & $170(1.8 \%)$ & $38(3.7 \%)$ & $86(0.4 \%)$ & $\begin{array}{l}138 \\
(45.0 \%)\end{array}$ & $\begin{array}{l}1237 \\
(28.6 \%)\end{array}$ & $213(10.0 \%)$ & $1493(3.9 \%)$ \\
\hline Intramedullary nailing & $2(0.3 \%)$ & $30(0.3 \%)$ & $4(0.4 \%)$ & $23(0.1 \%)$ & $12(3.9 \%)$ & $263(6.1 \%)$ & $18(0.8 \%)$ & $316(0.8 \%)$ \\
\hline Hemiarthroplasty cemented & $0(0 \%)$ & $632(6.8 \%)$ & $60(5.8 \%)$ & $\begin{array}{l}15,513 \\
(63.7 \%)\end{array}$ & $8(2.6 \%)$ & $\begin{array}{l}1455 \\
(33.6 \%)\end{array}$ & $68(3.2 \%)$ & $\begin{array}{l}17,600 \\
(46.4 \%)\end{array}$ \\
\hline Hemiarthroplasty uncemented & $0(0 \%)$ & $7(0.1 \%)$ & $2(0.2 \%)$ & $211(0.9 \%)$ & $1(0.3 \%)$ & $31(0.7 \%)$ & $3(0.1 \%)$ & $249(0.7 \%)$ \\
\hline Total hip arthroplasty cemented & 7 (0.9\%) & $232(2.5 \%)$ & $\begin{array}{l}208 \\
(20.2 \%)\end{array}$ & $5621(23.1 \%)$ & $19(6.2 \%)$ & $543(12.6 \%)$ & $234(11.0 \%)$ & $6396(16.9 \%)$ \\
\hline $\begin{array}{l}\text { Total hip arthroplasty } \\
\text { uncemented }\end{array}$ & $3(0.4 \%)$ & $4(0.0 \%)$ & $35(3.4 \%)$ & $86(0.4 \%)$ & $6(2.0 \%)$ & $15(0.3 \%)$ & $44(2.1 \%)$ & $105(0.3 \%)$ \\
\hline Total hip arthroplasty hybrid & $1(0.1 \%)$ & $4(0.0 \%)$ & $29(2.8 \%)$ & 215 (0.9\%) & $5(1.6 \%)$ & $19(0.4 \%)$ & $35(1.6 \%)$ & $238(0.6 \%)$ \\
\hline Arthroplasty other & $2(0.3 \%)$ & $6(0.1 \%)$ & $5(0.5 \%)$ & $147(0.6 \%)$ & $1(0.3 \%)$ & $20(0.5 \%)$ & $8(0.4 \%)$ & $173(0.5 \%)$ \\
\hline Non-operative & 19 (2.4\%) & $101(1.1 \%)$ & $5(0.5 \%)$ & $94(0.4 \%)$ & $5(1.6 \%)$ & $24(0.6 \%)$ & $29(1.4 \%)$ & 219 (0.6\%) \\
\hline Other/unknown & $49(6.2 \%)$ & 474 (5.1\%) & $43(4.2 \%)$ & 805 (3.3\%) & $32(10.4 \%)$ & 417 (9.6\%) & $124(5.8 \%)$ & $1696(4.5 \%)$ \\
\hline
\end{tabular}

classification into subgroups, i.e., include fracture tilt in the classification of uFNFs or the degree of displacement of bFNFs [19].

Previously, studies have used similar definitions of the bFNFs: a fracture medial to the intertrochanteric line [2]. However, these studies also included radiographic illustrations of fractures that extend laterally and distally into the trochanteric region and thus not according to the definition by AO/OTA [20, 21]. The AO/OTA definition of bFNFs is an extra-articular intracapsular fracture medial to the intertrochanteric line. Rotational instability is caused by the lack of muscular attachments to the

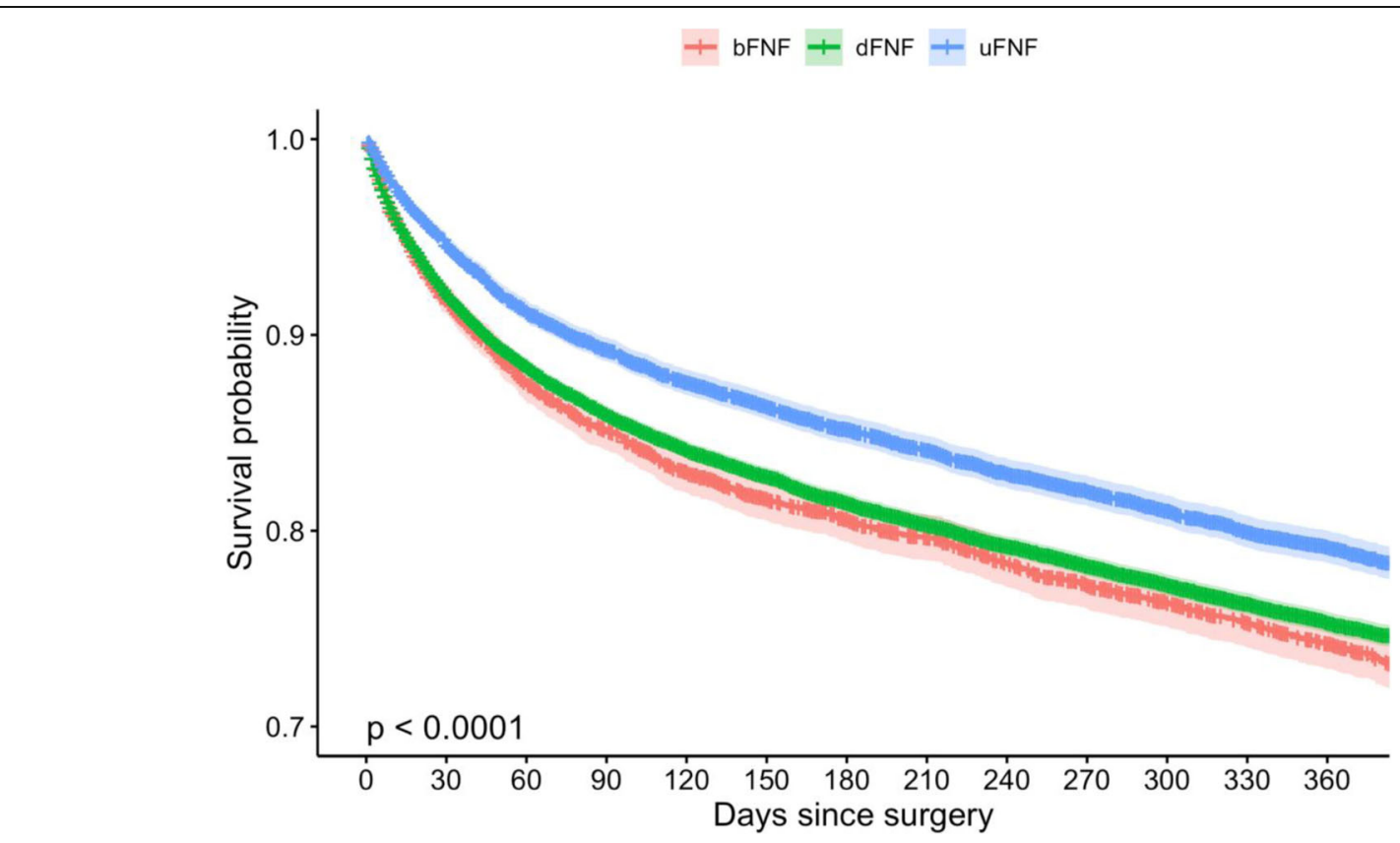

Fig. 3 Survival function estimated by the Kaplan-Meier with mortality as endpoint 
proximal fragment. Hence, this group of fractures shares characteristics with uFNF and dFNF [22]. No differentiation is made between undisplaced and displaced fractures. The literature contains data with a wide range of incidence rates and treatment options, which could partly explain the varying definitions of these fractures [2]. In the present study, a large number of observers with a wide range of experience from junior doctors to senior consultants performed the classification in a clinical setting using the AO/OTA definition of bFNFs.

\section{Treatment}

The type of surgical treatment depends on fracture localization, displacement, age, activity level, comorbidities, and surgeons' preferences and practice patterns. The use of non-surgical treatment is uncommon in our study of all types of fractures.

The leading treatment of uFNFs is closed reduction (if necessary, to reduce tilt) and IF with either 2-3 cancellous screws or pins. Of those $>60$ years, roughly $10 \%$ receive a primary hip arthroplasty, similar to a recent study from the Norwegian Hip Fracture Register [23]. These hip arthroplasties could be the clinical implication of fracture tilt on the lateral radiograph combined with those patients with coexisting degenerative joint disease or arthritic changes and a subsequent FNF [24-26]. The increased risk of treatment failure raises the question of whether hip arthroplasty has an advantage over IF [27]. There are no national guidelines in Sweden on how to treat uFNFs and whether to consider fracture tilt. A large nationwide register-based RCT has recently started in Sweden to study the benefit of hip arthroplasty in patients presenting with a uFNF [28].

Treatment of dFNFs in patients $>60$ years mainly consists of hemi- or total hip arthroplasty, with the majority receiving a hemiarthroplasty through a direct lateral approach (approximately two thirds of all patients) [29]. The decision on the type of arthroplasty is contingent on many factors, including surgeon comfort and the patient's age, health, and ambulatory status. In the present study, total hip arthroplasty was used in every fourth patient $>60$ years; although a high proportion, it does correspond to that found in other Western countries [30-33]. This effect could be a patient-driven phenomenon due to an increasingly active elderly population with higher functional demands. However, benefits to the elderly with a total hip arthroplasty over hemiarthroplasty remain in dispute with similar short-term results $[34,35]$.

The operative management of bFNFs is more diverse. Most patients $<60$ years are treated with IF and only a few have undergone arthroplasty. However, treatment for patients $>60$ years is almost evenly divided between IF and arthroplasty. Commonly used implants are screws or pins, SHD and, to a lesser extent, intramedullary nails. Several observational cohort studies have not found superiority of one over the other for the treatment of bFNFs $[8,9,36]$. However, biomechanical studies demonstrate that screws or pins have a lower load to failure than SHD or intramedullary nails [37]. Hip arthroplasty has been less studied. Observational data suggest similar functional outcomes in comparison to IF [38]. Future studies are warranted to refine the definition, prognosis and type of surgical treatment to improve the outcome of bFNFs. The degree of fracture displacement along with the type of fracture, age, level of activity, and comorbidities influences the surgeon's decision of treatment modality. Displacement, however, is not accounted for in the AO/OTA classification and cannot be analyzed in an observational study like ours.

\section{Mortality}

Overall mortality was similar to previous reports on FNF $[3,6]$. Although dFNF and bFNF had higher mortality than uFNF the previous groups were also older which makes comparison between the groups difficult.

\section{Strength and limitations}

Given that we used the SFR with $100 \%$ coverage at the end of the study period to describe the epidemiology of FNFs, our study has the advantage of a large sample size. However, we are unable to identify the overall incidence given the stepwise introduction and the present completeness of the SFR in Sweden.

Because of the varied definitions of bFNFs in the literature, comparison to our results is limited [2]. In our study, the widely used AO/OTA definition of bFNFs strengthens the generalizability of our findings. The treating physicians and orthopedic surgeons performed the registrations and classification of fractures in the SFR. Of note, validation studies in various segments found the classification systems to be as accurate as previous validation studies of femoral fracture classification [11].

\section{Conclusion}

The main treatment of uFNFs is IF with screws or pins, whereas hip arthroplasty is the primary treatment of dFNFs. bFNFs are more common than previously reported and treatment is more diverse and evenly distributed between IF and arthroplasty. Age and fracture type are factors affecting treatment choice. These results may help health care providers and clinicians better understand the panorama of FNFs in Sweden. 


\section{Appendix}

\section{Klassificering av fraktur}

\section{AO-klassifikation}

Trokantär/
Sub-
trokantär
fraktur
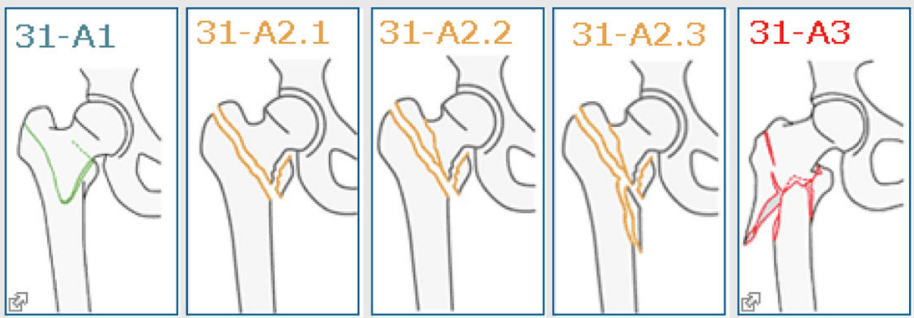

Cervikal

fraktur
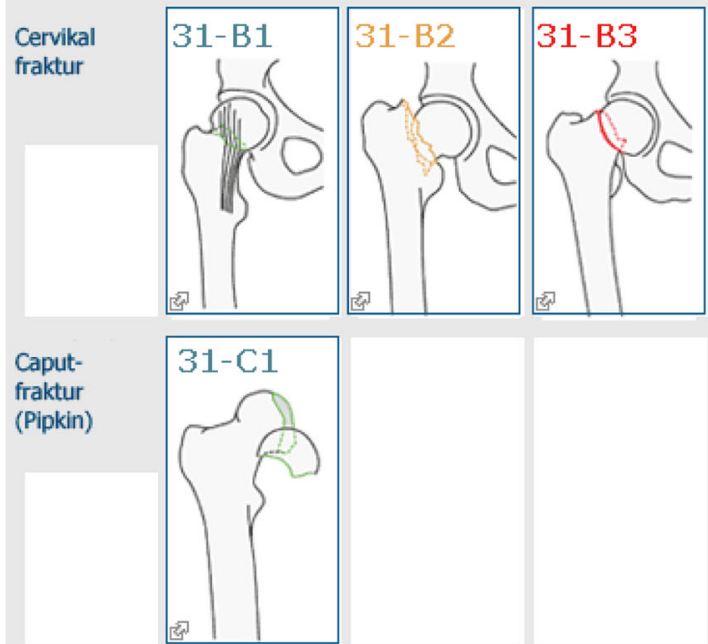

Ej kunnat klassificera/ej klassificerbar 


\section{Abbreviations}

FNF: Femoral neck fracture; bFNF: Basicervical femoral neck fracture; UFNF: Undisplaced femoral neck fracture; dFNF: Displaced femoral neck fracture; SFR: Swedish Fracture Register; IF: Internal fixation; SHD: Sliding hip device; IMN: Intramedullary nail; RCT: Randomized clinical trial

\section{Acknowledgements}

We wish to thank all the orthopedic surgeons who make time to enter fractures into the SFR.

\section{Authors' contributions}

JS initiated the study, performed statistical analysis, and wrote the manuscript. AB performed statistical analysis, wrote and reviewed the manuscript. AS and MM wrote and reviewed the manuscript. OW initiated the study, wrote and reviewed the manuscript. SM initiated the study, supervised JS, performed statistical analysis, and wrote the manuscript. All authors read and approved the final manuscript.

\section{Funding}

Open Access funding provided by Umeå University.

\section{Availability of data and materials}

The datasets used and/or analyzed during the current study are not publicly available. Data are available from the corresponding author on reasonable request.

\section{Declarations}

\section{Ethics approval and consent to participate}

The study was conducted according to the Helsinki Declaration's ethical principles and was approved by the Regional Ethical Review board (entry number 2020-05439).

\section{Consent for publication}

Not applicable.

\section{Competing interests}

The authors declare that they have no competing interests.

\section{Author details}

${ }^{1}$ Department of Surgical and Perioperative Sciences, Orthopaedics, Umeå University, Umeå, Sweden. ${ }^{2}$ Section of Orthopaedics, Department of Surgical Sciences, Uppsala University, Uppsala, Sweden. ${ }^{3}$ Department of Clinical Science and Education, Karolinska Institutet, Södersjukhuset, Stockholm, Sweden. ${ }^{4}$ Institute of Clinical Sciences, Sahlgrenska Academy, Gothenburg University, Gothenburg, Sweden.

\section{Received: 2 June 2021 Accepted: 30 August 2021}

\section{Published online: 15 September 2021}

\section{References}

1. Johnell O, Kanis JA. An estimate of the worldwide prevalence, mortality and disability associated with hip fracture. Osteoporos Int. 2004;15(11):897-902. https://doi.org/10.1007/s00198-004-1627-0.

2. Yoo Jl, Cha Y, Kwak J, Kim HY, Choy WS. Review on basicervical femoral neck fracture: definition, treatments, and failures. Hip Pelvis. 2020;32(4):17081. https://doi.org/10.5371/hp.2020.32.4.170.

3. Onativia IJ, Slullitel PA, Dilernia FD, Viezcas JMG, Vietto V, Ramkumar PN, et al. Outcomes of nondisplaced intracapsular femoral neck fractures with internal screw fixation in elderly patients: a systematic review. Hip Int. 2018; 28(1):18-28. https://doi.org/10.5301/hipint.5000532.

4. Parker M. Total hip arthroplasty versus hemiarthroplasty for intracapsular hip fractures. Bone Joint J. 2021;103-B(1):3-4. https://doi.org/10.1302/0301-62 OX 103B1BJJ-2020-1438R1.

5. Rogmark C. Further refinement of surgery will not necessarily improve outcome after hip fracture. Acta Orthop. 2020;91(2):123-4. https://doi.org/1 0.1080/17453674.2019.1706936

6. Dolatowski FC, Frihagen F, Bartels S, Opland V, Šaltytè Benth J, Talsnes O, et al. Screw fixation versus hemiarthroplasty for nondisplaced femoral neck fractures in elderly patients: a multicenter randomized controlled trial. J Bone Joint Surg Am. 2019;101(2):136-44. https://doi.org/10.2106/JBJS.18.00316.
7. Ekhtiari S, Gormley J, Axelrod DE, Devji T, Bhandari M, Guyatt GH. Total hip arthroplasty versus hemiarthroplasty for displaced femoral neck fracture: a systematic review and meta-analysis of randomized controlled trials. J Bone Joint Surg Am. 2020;102(18):1638-45. https://doi.org/10.2106/JBJS.20.00226.

8. Kim JT, Ha YC, Park CH, Yoo Jl, Kim TY. Single screw type of lag screw results higher reoperation rate in the osteosynthesis of basicervical hip fracture. J Orthop Sci. 2020;25(1):152-5. https://doi.org/10.1016/j.jos.2019.02.010.

9. Lee YK, Yoon BH, Hwang JS, Cha YH, Kim KC, Koo KH. Risk factors of fixation failure in basicervical femoral neck fracture: Which device is optimal for fixation? Injury. 2018;49(3):691-6. https://doi.org/10.1016/j.injury.2018.02.009.

10. Guo J, Dong W, Jin L, Yin Y, Zhang R, Hou Z, et al. Treatment of basicervical femoral neck fractures with proximal femoral nail antirotation. J Int Med Res. 2019:47(9):4333-43. https://doi.org/10.1177/0300060519862957.

11. Knutsson SB, Wennergren D, Bojan A, Ekelund J, Möller M. Femoral fracture classification in the Swedish Fracture Register - a validity study. BMC Musculoskelet Disord. 2019;20(1):197. https:/doi.org/10.1186/s12891-019-2579-z.

12. Curtis EM, van der Velde R, Moon RJ, van den Bergh JP, Geusens P, de Vries F, et al. Epidemiology of fractures in the United Kingdom 1988-2012: variation with age, sex, geography, ethnicity and socioeconomic status. Bone. 2016;87:19-26. https://doi.org/10.1016/j.bone.2016.03.006.

13. Waterman BR, Gun B, Bader JO, Orr JD, Belmont PJ Jr. Epidemiology of lower extremity stress fractures in the United States Military. Mil Med. 2016; 181(10):1308-13. https://doi.org/10.7205/MILMED-D-15-00571.

14. Biz C, Berizzi A, Crimi A, Marcato C, Trovarelli G, Ruggieri P. Management and treatment of femoral neck stress fractures in recreational runners: a report of four cases and review of the literature. Acta Biomed. 2017:88(4S): 96-106. https://doi.org/10.23750/abm.v88i4-S.6800.

15. Neubauer T, Brand J, Lidder S, Krawany M. Stress fractures of the femoral neck in runners: a review. Res Sports Med. 2016;24(3):283-97.

16. Odén A, Kanis JA, McCloskey EV, Johansson $H$. The effect of latitude on the risk and seasonal variation in hip fracture in Sweden. J Bone Miner Res. 2014:29(10):2217-23. https://doi.org/10.1002/jbmr.2250.

17. Harvey N, Dennison E, Cooper C. Osteoporosis: impact on health and economics. Nat Rev Rheumatol. 2010;6(2):99-105. https://doi.org/10.1038/ nrrheum.2009.260

18. Forsén L, Søgaard AJ, Holvik K, Meyer HE, Omsland TK, Stigum H, et al. Geographic variations in hip fracture incidence in a high-risk country stretching into the Arctic: a NOREPOS study. Osteoporos Int. 2020;31(7): 1323-31. https://doi.org/10.1007/s00198-020-05346-8.

19. J Orthop Trauma. 2018; 32:1 Supplement; https://www2.aofoundation.org/A OFileServerSurgery/MyPortalFiles?FilePath=/Surgery/en/_docs/AOOTA\%2 OClassification\%20Compendium\%202018.pdf (Accessed 22 Feb 2021).

20. Massoud El. Fixation of basicervical and related fractures. Int Orthop. 2010 34(4):577-82. https://doi.org/10.1007/s00264-009-0814-1.

21. Watson ST, Schaller TM, Tanner SL, Adams JD, Jeray KJ. Outcomes of lowenergy basicervical proximal femoral fractures treated with cephalomedullary fixation.J Bone Joint Surg Am. 2016:98(13):1097-102. https://doi.org/10.2106/JBJS.15.01093

22. Su BW, Heyworth BE, Protopsaltis TS, Lipton CB, Sinicropi SM, Chapman CB, et al. Basicervical versus intertrochanteric fractures: an analysis of radiographic and functional outcomes. Orthopedics. 2006:29(10):919-25. https://doi.org/10.3928/01477447-20061001-04

23. Kjærvik C, Stensland E, Byhring HS, Gjertsen J-E, Dybvik E, Søreide O. Hip fracture treatment in Norway: deviation from evidence-based treatment guidelines: data from the Norwegian Hip Fracture Register, 2014 to 2018. Bone Jt Open. 2020;1(10):644-53. https://doi.org/10.1302/2633-1462.110. BJO-2020-0124.R1.

24. Palm H, Gosvig K, Krasheninnikoff M, Jacobsen S, Gebuhr P. A new measurement for posterior tilt predicts reoperation in undisplaced femoral neck fractures: 113 consecutive patients treated by internal fixation and followed for 1 year. Acta Orthop. 2009;80(3):303-7. https://doi.org/10.3109/17453670902967281.

25. Sjöholm P, Otten V, Wolf O, Gordon M, Karsten G, Sköldenberg O, et al. Posterior and anterior tilt increases the risk of failure after internal fixation of Garden I and II femoral neck fracture. Acta Orthop. 2019:90(6):537-41. https://doi.org/10.1080/17453674.2019.1637469.

26. van der List JP, El Saddy S, Vos SJ, Temmerman OPP. Role of preoperative posterior tilt on the outcomes of internal fixation of non-displaced femoral neck fractures: a systematic review and meta-analysis. Injury. 2020;500201383(20):30988

27. Richards JT, Overmann AL, O'Hara NN, D'Alleyrand JC, Slobogean GP. Internal fixation versus arthroplasty for the treatment of nondisplaced 
femoral neck fractures in the elderly: a systematic review and meta-analysis. J Orthop Trauma. 2020;34(1):42-8. https://doi.org/10.1097/BOT. 0000000000001656.

28. Wolf O, Sjöholm P, Hailer NP, Möller M, Mukka S. Study protocol: HipSTHeR a register-based randomised controlled trial - hip screws or (total) hip replacement for undisplaced femoral neck fractures in older patients. BMC Geriatr. 2020;20(1):19. https://doi.org/10.1186/s12877-020-1418-2.

29. Swedish hip arthroplasty registry, Annual report 2019, s194. https:// registercentrum.blob.core.windows.net/shpr/r/-rsrapport_H-ftprotes_2019_ pdf_FINAL-B1lgibPvrv.pdf (Acessed 09 Feb 2021).

30. Miller BJ, Callaghan JJ, Cram P, Karam M, Marsh JL, Noiseux NO. Changing trends in the treatment of femoral neck fractures: a review of the American board of orthopaedic surgery database. J Bone Joint Surg Am. 2014;96(17): e149. https://doi.org/10.2106/JBJS.M.01122.

31. Harris IA, Cuthbert A, de Steiger R, Lewis P, Graves SE. Practice variation in total hip arthroplasty versus hemiarthroplasty for treatment of fractured neck of femur in Australia. Bone Joint J. 2019;101-B(1):92-5. https://doi.org/1 0.1302/0301-620X.101B1.BJJ-2018-0666.R1.

32. Khan AM, Rafferty M, Daurka JS. Hemiarthroplasty compared with total hip arthroplasty in fractured neck of femur: a shift in national practice? Ann $\mathrm{R}$ Coll Surg Engl. 2019;101(2):86-92. https://doi.org/10.1308/rcsann.2018.0123.

33. Gjertsen JE, Dybvik E, Furnes O, Fevang JM, Havelin LI, Matre K, et al. Improved outcome after hip fracture surgery in Norway. Acta Orthop. 2017; 88(5):505-11. https://doi.org/10.1080/17453674.2017.1344456.

34. Chammout G, Kelly-Pettersson P, Hedbeck C-J, Stark A, Mukka S, Sköldenberg O. HOPE-Trial: hemiarthroplasty compared with total hip arthroplasty for displaced femoral neck fractures in octogenarians: a randomized controlled trial. JB JS Open Access. 2019;4(2):e0059. https://doi. org/10.2106/JBJS.OA.18.00059

35. HEALTH Investigators, Bhandari M, Einhorn TA, Guyatt G, Schemitsch EH, Zura RD, et al. Total Hip Arthroplasty or Hemiarthroplasty for Hip Fracture. N Engl J Med. 2019;381(23):2199-208. https://doi.org/10.1056/NEJMoa1906190.

36. Chen CY, Chiu FY, Chen CM, Huang CK, Chen WM, Chen TH. Surgical treatment of basicervical fractures of femur-a prospective evaluation of 269 patients. J Trauma. 2008;64(2):427-9. https://doi.org/10.1097/01.ta.00002392 55.47280.6f.

37. Panteli M, Rodham P, Giannoudis PV. Biomechanical rationale for implant choices in femoral neck fracture fixation in the non-elderly. Injury. 2015; 46(3):445-52. https://doi.org/10.1016/j.injury.2014.12.031.

38. Davanzo D, Previtali D, Tamborini S, Filardo G, Fusco A, Bordoni V, et al. Comparison of the survivorship between arthroplasty and ORIF for basicervical femoral neck fractures in the overall population and in polymorbid patients. Orthop Traumatol Surg Res. 2020;14:102789.

\section{Publisher's Note}

Springer Nature remains neutral with regard to jurisdictional claims in published maps and institutional affiliations.

Ready to submit your research? Choose BMC and benefit from:

- fast, convenient online submission

- thorough peer review by experienced researchers in your field

- rapid publication on acceptance

- support for research data, including large and complex data types

- gold Open Access which fosters wider collaboration and increased citations

- maximum visibility for your research: over $100 \mathrm{M}$ website views per year

At $\mathrm{BMC}$, research is always in progress.

Learn more biomedcentral.com/submissions 